\title{
P03-19
}

\section{EVALUATION OF DYSLIPIDAEMIA RISK AMONG PATIENTS TREATED WITH ARIPIPRAZOLE: META ANALYSIS OF PLACEBO- AND OLANZAPINE-CONTROLLED STUDIES}

\author{
H. Peyro-Saint-Paul ${ }^{1}$, J.-Y. Loze ${ }^{2}$, S. Kaplita ${ }^{3}$, J. Han $^{3}$, R.A. Baker ${ }^{4}$, R. Cahn ${ }^{1}$, R. Owen ${ }^{3}$ \\ ${ }^{1}$ Bristol-Myers Squibb, ${ }^{2}$ Otsuka Pharmaceutical France, Paris, France, ${ }^{3}$ Bristol-Myers Squibb, Wallingford, ${ }^{4}$ Bristol-Myers Squibb, \\ Princeton, USA
}

Aims: To evaluate dyslipidaemia risk among patients with schizophrenia treated with aripiprazole or olanzapine.

Methods: Pooled analysis of the aripiprazole clinical database, including studies of $\geq 7$ days with at least an oral aripiprazole monotherapy arm. Mean changes from baseline to endpoint and shifts from normal to abnormal lipid levels were calculated.

Results: Seventeen placebo- and five olanzapine-controlled studies ( 3 weeks->3 years) of adult patients ( $\geq 18$ years) were included Mean changes (LOCF) in lipids were similar between aripiprazole and placebo for all lipid parameters; aripiprazole showed significant improvements versus olanzapine ( $\leq \leq 0.01)$. The incidence $(O C)$ of switching to abnormal lipid levels from baseline normal was similar between placebo and aripiprazole, and significantly lower with aripiprazole than olanzapine for most measures.

Conclusion: Despite limitations inherent to pooled analyses, these findings lend further support to the differential profile of atypicals, with aripiprazole showing effects on lipids comparable with placebo.

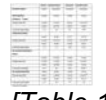

[Table 1] 